\title{
Language, neoliberalism, and the commodification of pedagogy
}

\section{Carlos Soto ${ }^{a *}$ and Miguel Pérez-Milans ${ }^{\mathrm{b}}$}

\author{
${ }^{a}$ Faculty of Education, University of Hong Kong, Hong Kong S.A.R.; ${ }^{b}$ Department of \\ Culture, Communication and Media, UCL Institute of Education, UK
}

Correspondence details

Carlos Soto*, cesoto@hku.hk

660 Meng Wah Complex, University of Hong Kong, Pokfulam Road, Hong Kong

Miguel Pérez-Milans

620A, 20 Bedford Way, London, United Kingdom, WC1H OAL

Notes on contributors

Carlos Soto is Lecturer in the Faculty of Education, University of Hong Kong. His recent publications focus on documenting and interrogating his development of a critical education practices while working in Hong Kong schools serving students from South Asian heritage communities. He continues working directly on education projects with primary and secondary school students and is preparing a book on developing a critical pedagogy in the context of neoliberal reforms, to be published by Routledge.

Miguel Pérez-Milans is Associate Professor in Applied Linguistics at UCL Institute of Education, University College London. He is author of the book Urban Schools and English Language Education in Late Modern China: A Critical Sociolinguistic Ethnography (Routledge Critical Series in Multilingualism, 2013). He has also edited monographs in the form of special issues: Multilingual Discursive Practices and Processes of Social Change in Globalizing Institutional Spaces (International Journal of Multilingualism 11[4], 2014), Language Education Policy in Late Modernity: Insights from Situated Approaches (Language Policy 14[2], 2015), and Reflexivity in Late Modernity: Accounts from Linguistic Ethnographies of Youth (AILA Review 29[1], 2016). 


\section{Language, neoliberalism, and the commodification of pedagogy}

Although it has revealed the material conditions under which language education programs are implemented worldwide, research on neoliberalism and language commodification has not yet adequately centred pedagogy. Thus, processes commodifying 'objects' other than language as product go unnoticed in educational settings. Drawing on a four-year ethnography in Hong Kong, this article details the processes whereby social actors formulated pedagogy as a 'commodity register' (Agha, 2011) to create distinction, index normative roles and desirable social personae. It also shows how some actors concurrently constructed pedagogy as a resource for advancing ethnic-group activist concerns, leading to unpredicted tensions and forms of inequality.

Keywords: language; neoliberalism; commodification; pedagogy; discourse; education; Hong Kong

\section{Introduction}

As nations intensify economic selective deregulation, internationalization, and privatization, (Harvey, 2005), schools adapt to centralized policies, since the state retains control over distribution and allocation of symbolic resources, through monitoring, evaluation, measurement and standardization. Simultaneously, schools face a political discourse of autonomy insisting on accountability for providing work forces with specific sets of (linguistic and non-linguistic) skills (Urciuoli, 2008; Heller, 2010) and are also pushed to create social distinction by turning languages perceived as 'international' into symbolic indexes of competitiveness.

This is evidenced in public educational systems where English is becoming a widespread medium of instruction. Swept by bilingual education programs funded by national and supranational bodies, schools have institutionalized English, as an add-on subject or as an instructional medium. These moves are rationalized with discourses emphasizing preparation of citizens for competition in the new global market (see 
overview by Codó \& Patiño-Santos, 2017). In educational systems traditionally using English for instruction, this logic has also contributed to the institutionalization of other languages, including Mandarin Chinese (see Pérez-Milans, 2015, for United Kingdom's case).

Such changes are recursively framed as related to shifting policies, discourses and ideologies about economic development, collectively termed as neoliberalism, that impact how the relationship between the state, the market and the individual is imagined (Foucault, 2008; Harvey, 2005). Neoliberalism understands the market and competition not as natural reality, but as requiring the regulatory practice of government. Moreover, it proposes extending economic rationality to all social life, so individuals allocate limited resources to their goals (Lemke, 2001), and also manage anxiety, induced by self-reflexivity, regarding one's material and symbolic well-being (Neilson, 2015).

Critically-oriented work linking neoliberalism to escalating social inequalities has re-revealed how practices and discourses about language and communication shape, and are shaped by, changing forms of political economy (Heller, 2010; Flubacher \& Del Percio, 2017). Away from languages discursively constructed as emblems of ethnonational belonging that regulate access to unified national markets, these new neoliberal arrangements are linked to commodification processes regularly framing language as an object 'rendered available for conventional exchange in the market' (Heller, Pujolar \& Duchêne, 2014, p. 545). Thus, access to late-capitalist service-based economic industries in the new trans-national market is dependent on individual social actors' ability to master new multilingual practices in which monoglossic norms (e.g., bilingualism as parallel monolingualisms) and prestigious discourse registers regulate access to material resources in ways that contribute to reproducing existing 
socioeconomic hierarchies in each national context (Duchêne \& Heller, 2012; see also Jaspers, 2018).

Under such conditions, individual competitiveness becomes a principle, as ' $[\mathrm{t}] \mathrm{he}$ dynamics that turn market-governing processes into modes of social organisation and modes of self-constitution transfer the process of self-capitalisation to subjects who must enhance their own productivity by their own decisions' (Martín-Rojo, 2018, p. 555). Consequently, speaking subjects become objectified through equating the competent speaker of profitable languages in a flexible market, one the one hand, and an entrepreneurial project in human resources and managerial literature, and in language industries, on the other (see also Allan \& McElhinny, 2017). However, as Del Percio (2017) notes, imagining social actors as fully responsible for employability, via selftraining and self-actualization, conceals structural accounts of un-employability.

In sum, this work on neoliberalism in education reveals: a) the material conditions under which new language education programs are implemented; b) the social inequalities engendered by them; and c) how such programs impact the daily lives of the institutions and agents implementing them (Codó \& Patiño-Santos, 2017). However, this sociolinguistic literature has not yet adequately centered pedagogy, which in our view, leaves processes commodifying 'objects', other than language as a product, unexplored. Indeed, English-medium based educational models are spreading internationally, with sets of educational values and principles - and the social personae indexed by them - functioning as key symbolic resources for culturally producing distinction (Jaworski \& Thurlow, 2017), instead of just the language of instruction (see Sunyol, 2017). In this article, we build understanding of the three strands above by exploring the discursive commodification of pedagogy within an English-medium 
program in Hong Kong, a process set against pedagogy as a resource for enacting social change.

In this light, we return to our 4-year ethnographic and discourse-based research (Pérez-Milans \& Soto, 2014; Pérez-Milans \& Soto, 2016), focusing on a low-prestige secondary school, which we call $\mathrm{MAT}^{1}$, that underwent a major reorganisation to conform to wider institutional transformations in the Hong Kong educational system. Facing difficulties in meeting the minimum government-required student in-take to keep maximum public funding, the school set up and marketed an English-medium-ofinstruction-based (EMI, hereafter) section to attract working-class students with primarily Nepali and Pakistani backgrounds (so-called 'Ethnic Minorities' in the Hong Kong context) while maintaining a Chinese-medium-of-instruction-based (CMI, hereafter) section serving the school's majority working-class ethnically Chinese student population, and keeping the EMI section unavailable to them. While the choice of 'English' could be seen here as a 'key marketing device' in itself (Urciuoli, 2003), the new school policy's enactment placed discourses and values of pedagogy at the centre of daily-lived struggles.

In what follows, we first outline our research approach to pedagogy through the lens of commodification (Section 2), followed by an account of the educational reforms that created the institutional conditions that we describe at MAT, in the context of the political-economic reforms of post-1997 Hong Kong (Section 3). Later, we turn to MAT, focusing on the process of enrolment of ethnic minority (EM hereafter) students at the school and the creation of spaces for tensions and contradictions that participants navigated and used for enhancing strategic reflexivity (Section 4). We conclude with a

\footnotetext{
${ }^{1}$ All names in this article, aside from author names, are pseudonyms.
} 
discussion of the implications of our findings for further critical language-based research in the field of education, as well with consideration of the limits and possibilities for the emergence of new structures of feeling and cultural structures for action within local markets, both as new inequalities, and as interactional subjective investments in a better future (Section 5).

\section{Discourse, pedagogy and commodification: A research approach}

Our social/discursive approach sees pedagogy as knowledge that is socially (historically, politically, economically) situated, and rejects its representation as ideologically free (Apple, 1979; Harris, 1979; Popkewitz, 1984; Simon, 1987; Giroux, 1988). We also align with Pennycook's (1989, pp. 608-609) reminder that knowledge about pedagogy must be examined without taking for granted that it reflects what actually happens in the daily life of situated educational spaces. These claims offer two important avenues for studying contemporary neoliberalisation processes in education through critical and communication-based lens: 1) a focus on politically and historically situated forms of knowledge about teaching and learning, including an interest in the socioeconomic consequences that these have; and 2) an epistemological direction on how to adequately describe the production, circulation and consumption of such knowledge forms, so that we can account for what actually happens in specific settings.

The first avenue places pedagogy as a relevant 'discursive space' (Heller, 2007) in which who gets to decide what counts as proper teaching and learning cannot be detached from wider institutional and historical struggles over legitimization of broader social/moral categories concerned with competence and citizenship - including the very conceptualization of 'language' in the case of language education (Dendrinos, 1992). In choosing this path, we acknowledge that drawing on Karl Marx's (1904 [1859]) notion of commodity, we risk extending the metaphor of the market where it may not be an 
ontological reality (Block, forthcoming). But we believe understanding pedagogy as a discursive terrain does not prevent us from situating it in a wider market of economic exchanges in which it acquires use and exchange value with consequences for the social relations of labor out of which such forms of knowledge are produced. Taking onboard criticisms that question language commodification on the grounds that language is seldom constructed as a bounded object of conventional exchange in the market (see McGill, 2013), we think that pedagogy is relevant for examining discursive practices without concealing the so-called 'material realities of production of the commodity' (Simpson \& O’Regan, in press).

The second avenue demands an explicit epistemological approach as to how institutional processes of commodification are to be empirically addressed. Regardless of whether or not our position favors a separation of discursive practices and material realities, we hold the view that any research about the social world needs to engage with human activities, and that these activities are always mediated by discursive/semiotic practices. This view is aligned with Agha's (2011) concern that in studies of commodification there has been considerable attention to exchange-value at the expense of use-value - using Marx's (1904 [1859]: 34) conceptualization of the different values of commodities. Accordingly, this article analyses the situated dynamics of discourse production, circulation and consumption that typify pedagogical values as commodities, with attention to how social actors negotiate stances, social personae, social relations, and attribution of value through daily activities, as well as to the socio-institutional consequences they face in accessing material and symbolic resources.

We do so by drawing on ethnographic approaches to communication in which discourse is conceptualised as a mode of practical action (Goodwin \& Duranti, 2000). Stemming from a long-standing linguistic anthropological tradition first laid down by 
Malinowski (1923), these approaches presuppose that meaning does not come from contemplation of things, or analysis of occurrences, but in practical and active acquaintance with relevant situations. In other words, discourses (or texts) are seen as empty signifiers that only acquire meaning through instances in which such discourses are re-contextualised and transformed through the meaning-making practices of those acquainted with them (Silverstein \& Urban, 1996; see also Blommaert, 2005, pp. 39$67)$.

With these ontological and epistemological lenses as the backdrop, we conducted a 4-year joint investigation that began in 2011 at MAT school. Carlos (article's co-author) taught English and Liberal Studies and Miguel (article's co-author) conducted research in Carlos' classes. Following Carlos' departure from the school in the fall of 2014, we continued working for another nine months with ten students from MAT who joined a student research program we designed and ran at a community centre. Throughout these four years, our research also involved a network of other social actors, including school teachers, social workers, ethnic minority community leaders, and university researchers. Our data corpus includes: audio/video recordings of school and out-of-school interactions, field notes, classroom materials, school's institutional documents, screen captures of social media and messaging platform practices, photos, interviews, questionnaires, online and print media coverage involving our participants and our participants' multimedia files from self-recorded events.

In making sense of data, we scrutinized the discursive construction of pedagogical progressivism both as a commodity register (Agha, 2011) and a resource for projects of empowerment; that is to say, as an 'emblematic sign' (Agha, 2007) attached to a set of aspirational values and types of personae that became reflexively manipulated for different purposes by different social actors at MAT. Though this 
discursive work contributed to attract the desired student ethnic profile, it also led to unexpected dynamics among the school's administrators, newly-hired teachers, and parents and students across the English- and Chinese-based divisions, over normative forms of participation (i.e. appropriate ways of teaching/learning) and social categories (i.e. 'good' and 'not-so-good' teachers, administrators and learners).

But before developing our story of pedagogy at MAT, we must detail the institutional conditions that allowed opening the International Section (IS hereafter), in the context of (neoliberal) political economy of the region shifting after Hong Kong's handover to China.

\section{MAT, quality education and Hong Kong post-1997 reforms}

MAT was founded in 1984 by an industrialist and philanthropist with the aim of helping working-class students through pre-vocational courses that would also upgrade the industrial labour force's skills for a growing economy. After the management of the school was designated to an industrial organisation, in-line with government's desire to have sponsoring bodies be accountable for provision of education, the school's official medium of instruction became Chinese (spoken Cantonese and written traditional characters), following an official policy promoting 'mother-tongue' instruction in Hong Kong. In addition, the school's curriculum was reconfigured, from pre-vocational to academic, following government recommendations to move away from technical schools.

Since then, MAT has been shaped by larger political, educational, and demographic transformations that together yielded a situation in which EM students acquire specific value, prompting institutional reorganisation for schools seeing them as a means to increased enrolments, and in the case of MAT, also allowing pedagogy to come to the fore of its efforts to establish distinct exchange value. The changes in the 
education system have been concerned with the implementation of so-called 'quality education', a series of reforms spanning three decades in context of Hong Kong's transition from British colonial rule to Chinese sovereignty. Aimed at meeting the new Special Administrative Region's needs to reintegrate with China and to position itself for competitiveness in a global knowledge-based economy, these reforms have been conceptualised as an attempt to re-align the school system, families, and individual students within it towards competitiveness and flexibility in the face of unpredictable economic future (see Cheong, 2009 for an overview).

Among these series of reforms, the most recent wave has argued for the necessity to 'liberate student learning' through a 'paradigm shift' that promotes a new 'flexible and open curriculum framework' in order to steer education 'from a textbookoriented and teacher-centred approach, to a multi-dimensional, interactive and studentcentred learning approach', all of it in connection with emphasis on the importance of ‘inquiry', 'interactive learning', 'information technology’, 'life-long learning', 'wholeperson development', 'creativity', 'critical thinking', 'collaboration' and 'internationalization' as categories qualifying the new educational approach (Education Commission, 2000). But not all schools can equally access resources to enact this vision.

Through policies that have expanded school privatisation and marketisation in Hong Kong, two school categories have been better positioned to exploit these new discourses, based on the flexibility they are granted in curriculum and pedagogical development, instructional medium, teacher hiring, and student admission procedures. First, Direct Subsidy Scheme (DSS hereafter) schools operate as semi-private feecharging institutions, and their expansion has been discursively justified as improving quality and bringing diversity and choice to the education sector. Second, international 
schools offering full-time non-local curricula and examinations (Education Bureau, 2012) have been expanded to address concerns from business communities of insufficient international school places for children of expatriate workers, and also to meet aspirations of local and post-1997 returnee families for the 'competitive edge' perceived as provided by international schools, including a more flexible, less rigid, and interactive approach, and greater opportunities to enhance English proficiency (p. 17). Both DSS and international schools further distinguish themselves by offering EMI international curricula, most often the International Baccalaureate (IB, hereafter) curriculum.

Collectively, these reforms have shaped competitive relationships between schools for students not just as bodies, but also as desirable goods and investments in the maintenance and building of a school's economic and social capital. 'Good students' have been imagined not just as fulfilling an enrolment quota, but also as delivering academic performance and social indicators that could build the school's academic standing and perceived social prestige (Leung, 2013). Schools have advertised themselves to improve their student intake numbers and quality, as a survival and/or growth mechanism. Parents, based on their means and desires, have turned to an expanded commercial educational services sector to improve their children's' performance in school admissions, assessment, and ranking processes.

In addition, changing demographics have strengthened competition since the mid-2000s among low-prestige educational institutions, as wealthier and highereducated families opted for EMI-based and higher prestige schools, including DSS and international schools (Woo, 2014), leading to increasing social segregation in the school system and division of education experiences by socioeconomic class (Zhou, Cai, \& Wang, 2016). Such demographic transformations refer to two trends: 1) a falling birth 
rate in Hong Kong which reduced the overall student pool, leaving many schools incapable of drawing sufficient enrolment numbers with the threat of reduced government subsidies; and, 2) a significant increase in EM students, often descendants of former Pakistani and Nepalese British colonial workers and security forces who gained the right to abode and settled their families in Hong Kong post-1997.

Under these conditions, some principals and school management bodies have been reported as looking 'on ethnic minorities as saviors so as to avoid school closure' (Chan, 2013, p. 1). Nevertheless, although schools frequently offer and promote EMI classes and amenities related to students' heritage languages, religions, and interests, the social image of EM students is far removed from prevailing notions of 'good students' discussed above; rather, they are reported mainly as academically struggling, marginalised from the greater society with limited social mobility, and depicted most often as either victims or trouble-makers in the local media (Erni \& Leung, 2014).

At MAT, limited resources, CMI teaching, and institutional experience lacking in the discursive display of values emblematically linked to pedagogical progressivism, placed the institution in a vulnerable position for contending with new expectations for market participation and academic performance. Thus, for the school's administrators, re-orientating from serving ethnic Chinese to EM students, via an EMI section, was a suitable adaptation to ongoing transformations. It created a survival method and an opportunity to improve overall academic performance - based on these administrators' understanding that EM students are generally more competent in English than the ethnic Chinese students in the CMI section.

The story of pedagogy at MAT is situated at the intersection of these dynamics. In the following section, we examine the tensions emerging in the enregisterment (Agha, 2007) of pedagogical progressivism as a commodity in this setting; that is to say, 
we describe the process whereby certain discursive elements, or diacritics, things that act as perceivable markers (pp. 249-250), became emblems of pedagogical progressivism, with focus on the values attributed to them and the social relations (including of labor) that the relevant actors in the school negotiated upon its enactment.

\section{Pedagogy as a discursive space at MAT school}

A key hire at MAT was Lagan, a male of Nepali heritage, who in late 2010 began as a liaison officer assisting in student and teacher recruitment for the IS. Lagan had a fitting profile: prior working experience in primary schools serving EM students and participation in Nepalese-based community organisations. He was an important agent in developing and maintaining pedagogy as a discursive space and became central in positioning the commodification process alongside activism.

Lagan agreed with the new promotional tactic but sought concessions, which the school granted, but would later contest: bus services for students living beyond the local district, Nepalese language classes, and literature-based English curriculum. $\mathrm{He}$ also recruited teachers, including Carlos, who he thought could teach future international curricula, and who might align with his EM advocacy in Hong Kong. Lagan sought greater social and political recognition and inclusion for EM groups and re-allocation of educational resources, particularly to address EM youth, who he saw as facing a crisis pertaining to emotional, physical, and social well-being. But successfully, and continuously, competing against other schools for EM student enrolments required MAT to balance demands, MAT had to create distinction in how the IS and its value to students were perceived by various actors while conforming to the government's accountability and performativity measures.

This distinction involved changing the promotional strategy, from offering future international qualifications to displaying a set of values and principles closely 
aligned with the Hong Kong government's discourse of educational reform. Such a shift placed pedagogy in a central position to the management of anxieties over the uncertainty of future enrolments, thus becoming not solely a resource for recruitment, but also a site for conflict and affect where actors negotiated stances, alignments and dealignments. These interrelated aspects will be addressed below, in turn.

\subsection{Pedagogy as resource for recruitment}

When Lagan was chosen to head promotional efforts in late 2011, he wished to secure larger enrolments and used the IS to advance his EM empowerment agenda. Initially, Lagan envisioned implementing the IB curriculum as a platform for aiding socioeconomically marginalised students remain competitive against more privileged students. But staff consensus in the EMI section judged offering international qualifications as unrealistic based on limited resources at MAT and what they considered as relatively low English academic skills of the section's students. In this context, the discursive enactment of pedagogical progressivism, as a commodity semiotically formulated along lines of distinction, emerged by mid-2012 as a new resource for recruiting students and staff, and was achieved through production and circulation of promotional materials such as a new IS brochure.

The previous year's brochure cover featured the school campus, and its eight pages were separated into three sections describing the school's curriculum subjects, outlining pathways to future tertiary studies locally and abroad via local and international secondary qualifications, and explaining the local and international public examinations students would potentially sit. Field notes and follow-up conversations show that Lagan judged the brochure's design as 'too local' and not connoting internationalization; aesthetically, it was multi-coloured and made use of cartoon graphics, and the curriculum subjects listed was not distinctive compared to similar 
schools. Instead, he opted for a streamlined aesthetic, doubled the pages to include more images, and featured a group of ten uniform-clad students of Nepalese, Pakistani, and Chinese heritage on the cover.

While the content of the brochure was largely developed by Lagan, Carlos saw an opportunity to articulate a distinct educational vision, and edited the text to focus the content and make it linguistically clear, while final reviews were conducted by other administrative staff. The new brochure only listed curricular subjects and allotted three pages to explaining a philosophy underpinning the curriculum and its teaching. Another distinguishing feature were messages from the school's supervisor and principal, and testimonials as 'Parent, Student and Community Voices' from teachers (including Carlos), parents, students, and Miguel. Figure 1 shows a brochure page.

\section{Figure 1. IS brochure page}

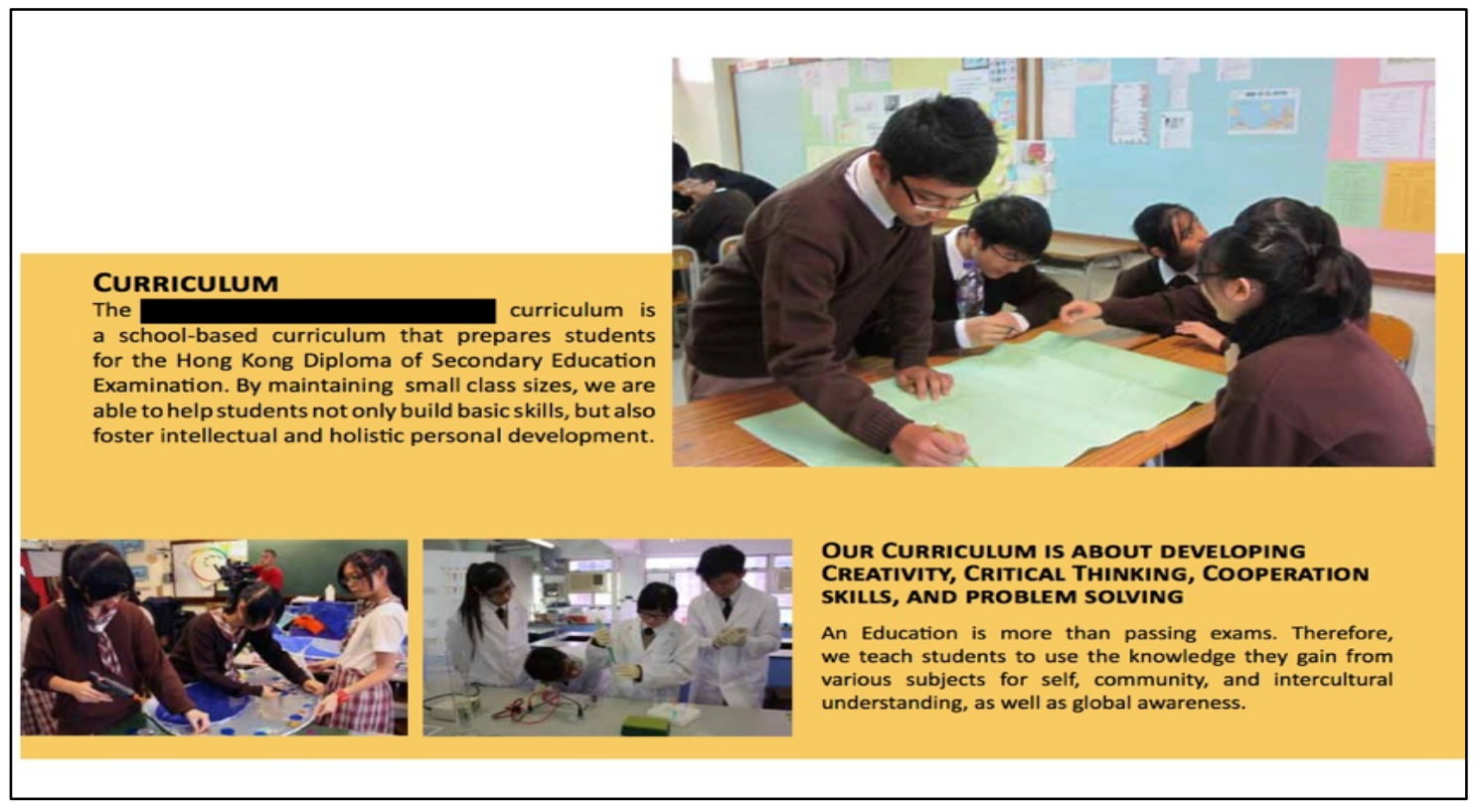

Preceded by introductions from the school's principal and the school supervisor (i.e. the representative of the sponsoring industrial association) in which MAT is presented as 'encouraging diversity and creating a multicultural harmonious environment', and the 
IS as having 'a team of dedicated and professional teachers and supporting staff [that] is committed to providing those in need of it a tailor-made school curriculum', the brochure features a pedagogical approach closely aligned with the emblematic principles of the paradigm shift proposed by the Hong Kong government to 'liberate student learning' and to bring a 'flexible open curriculum' and 'internationalization', in contrast to traditional un-individualised examination-focused and teacher-centred traditions (see previous section). This emerges from the two texts on both sides of Figure 1. On the left side, the focus on preparing students for the Hong Kong Diploma of Secondary Education Examination is followed by a description of 'small class sizes' as a means to provide students with more than basic skills and to foster 'intellectual and holistic personal development', thus departing from traditional exam-oriented approaches associated with classroom massification.

On the right side, the contrast with such approaches is reinforced through an opening statement that claims that 'An Education is more than passing exams', leading to a description of the IS as a place in which the teaching and learning of knowledge is linked to individual, community-based, and internationalization values. Also, this statement is headed by the key categories foregrounded by the Hong Kong government in its official attempts to steer education from textbook-oriented to student-centred learning: 'creativity', 'critical thinking', 'collaboration', 'problem solving'. This discursive alignment with the government's stance also coheres with the three accompanying photographs in the brochure which feature students working collaboratively, in small groups, on what seem to be inquiry-oriented tasks.

The same themes are found in the brochure's testimonials, which define normative roles for administrators, teachers, students, and parents as both agents and subjects of progressive pedagogy. Testimonials from the school's supervisor and 
principal together rationalize the administrative role as providing equitable support and 'international quality' resources for students to build 'intellectual curiosity', 'fulfil academic potential' and 'make positive differences'. While teacher testimonials assign their role as attending to intellectual and socio-emotional needs of students via activities that 'motivate', 'nurture', inspire, and 'develop [students'] interests'. Both students and parents are portrayed as taking stances against textbook and exam-oriented models of pedagogy, termed as 'spoon-feeding education' and 'the traditional system' in testimonials, and favouring the approaches described by teacher testimonials and elaborated within the brochure. Finally, students are not only normatively aligned with the pedagogical approach articulated, they are also positioned as beneficiaries of a pedagogy meant to socially, emotionally, and intellectually impact their subjectivities. Pedagogy's function is thus presented as one that does not form 'parrots' who recite what their owners tell them, and instead potentially transforms students into more 'selfconfident and independent' beings who are more 'positive' and interested in their academic studies. These roles and functions are further ratified by a testimonial from Miguel, whose research role was occasionally highlighted for promotions by Lagan.

Beyond institutional promotional materials, Lagan and other actors aligned with him involved students in school promotion and appeals for resources and collaboration to audiences of educators, community activists, and families via in-person, radio, newspaper stories, and online presentations. Despite this development, conflicts around progressivist pedagogy and its associated principles, categories, and normative roles that began as disagreements regarding what constituted appropriate teaching in the IS, took on increased intensity and new dimensions after 2011. 


\subsection{Pedagogy as a site for conflict and affect}

During the 2011-2012 academic year, pedagogical progressivism's enactment became highly contested in daily life. In opposition to the typifying values of pedagogical progressivism, some teachers and administrators more closely linked with the CMI section at MAT believed that more standardised formal curriculum and extra-curricular activities across CMI and EMI sections would make school experiences more similar, and therefore fairer for all students, though in effect, this would mean the dissolution of the IS. Concurrently, actors had to consider government performativity and accountability measures that contradicted its own reform-based discourse of pedagogical progressivism.

Such measures included a testing regime partly meant to gauge the 'value added' to students via the school's instruction, institutional quality inspections of curricular documents and student work, and recommendations for curricular standardisation, including of English language teaching across the CMI and EMI sections. From these tensions, a recurring pattern arose and intensified, from the fall of 2012, of administrative legitimation of pedagogical progressivism for promotional purposes against questioning of its suitability in daily practice and the reallocation of staff and spaces that made its enactment feasible.

The promotional efforts around pedagogical progressivism together with the ensuing conflicts opened spaces for strategic reflexivity by students who, in recognising the rift between progressivist pedagogy's commodity register and their lives' precariousness, appropriated pedagogical progressivism to engage in forms of activism against MAT. They did so by relying on their marginalising social experiences and disaffecting school conditions in Hong Kong as narratives that contrasted with MAT's peaceful and conflict-free portrayals in its brochures (see Pérez-Milans \& Soto, 2016 for an in-depth analysis of activism as a contesting form of discourse register among 
students in MAT's IS). As promotion via pedagogical progressivism continued, conflict also materialised from some parents' anxieties about the IS's direction and how they and their children might be left unserved.

While many of these parents exhibited desires for their children to engage with pedagogical progressivism, they also expressed insecurity about whether or not the teachers capable of the emotional and intellectual labour necessary to enact it would be available. Parents first expressed dissatisfaction in late 2012 as teachers became reallocated to different groups of students, and later in July of 2013 when IS teachers lacked new employment contracts, their positions contingent on whether a sufficient number of students would enrol for the fall of 2013. Many parents complained vociferously, prompting the principal to write a letter providing assurance and an explicit realignment with stance of pedagogical change: 'As for pedagogical approaches and curriculum development, we agree on the need to vigorously revamp our curriculum to cater for the diverse socio-emotional and educational needs of [NonChinese Speaking] students'.

Following these events, and staff's resistance towards promoting the IS without the security of employment contracts, the minimum new enrolment required by the government was barely secured, and the pattern of tension began anew for the 20132014 academic year. But the precarity under which MAT operated, and the unease and shifting alignments regarding the school's promotional efforts, had to be negotiated and reconciled by the school actors in their daily routines. Through a great deal of emotional work and sustained attempts to overcome conflict, some of these mundane acts of intersubjective realignments crystallised into long-term trajectories of collaboration. This is the case of Carlos and Jane, the English department head at MAT. 
Jane was hired by MAT's administrators in 2011, partly to head preparations for a governmental quality assurance inspection emphasising accountability and performativity. She aimed to raise CMI section English examination results CMI section through curriculum emphasising exam preparation, and this focus contributed to her initial clashes with Carlos about what counted as appropriate teaching, learning, and assessment within an academically underperforming school. But eventually Jane became supportive of him after working with IS students in 2012. She contributed to promoting pedagogical progressivism, and to circulating discourses of EM students in a crisis exacerbated by traditional pedagogical approaches. These past struggles and realignments over pedagogy are negotiated throughout an emotionally charged recount of events, actors and circumstances that allowed them to perform social reconciliation in Extract 1 below, as part of a research interview that Miguel conducted in May of 2014. Nine minutes into the interview, the conversation goes as follows:

\section{Extract 1. 'When we had a lot of fights'}

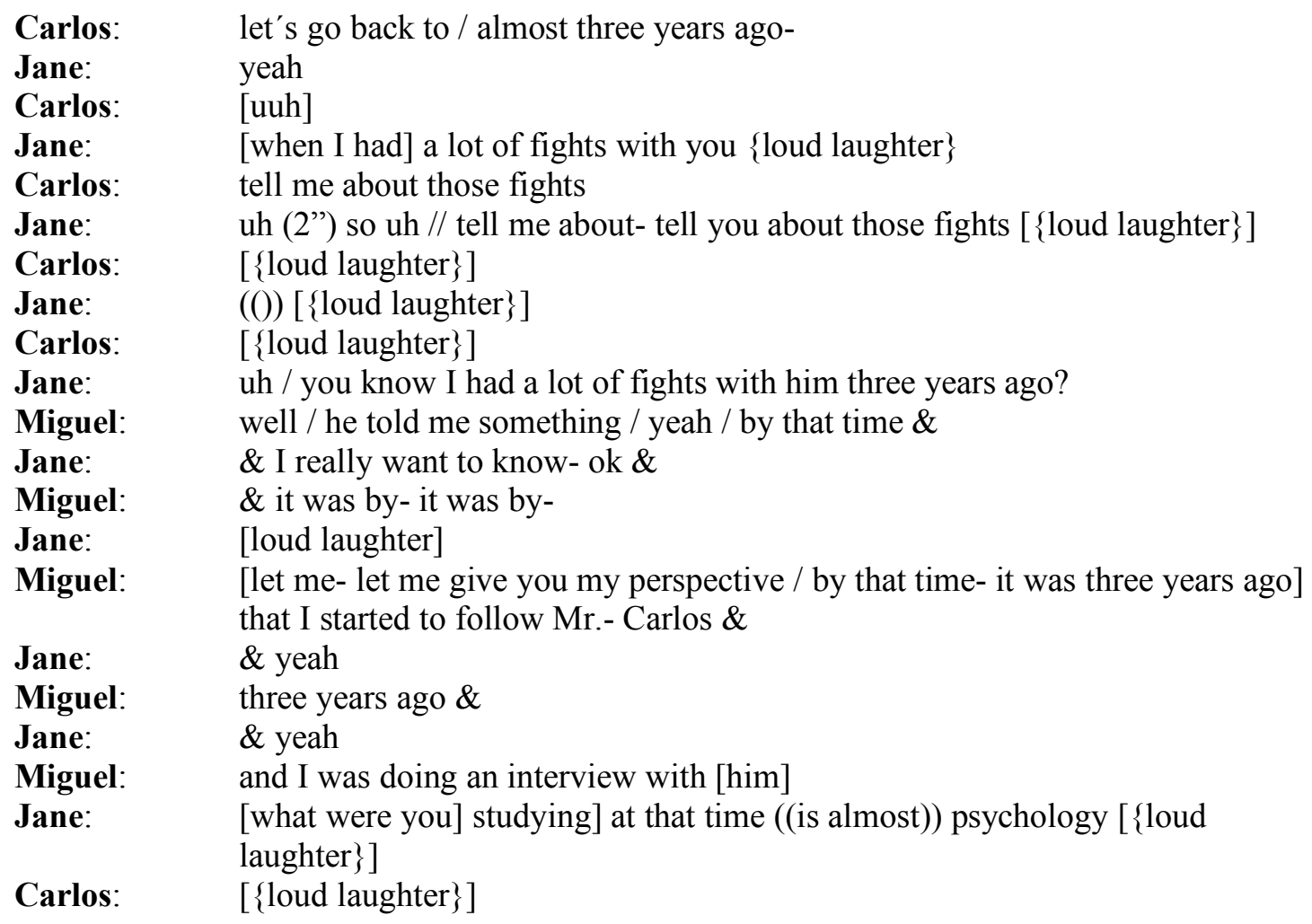




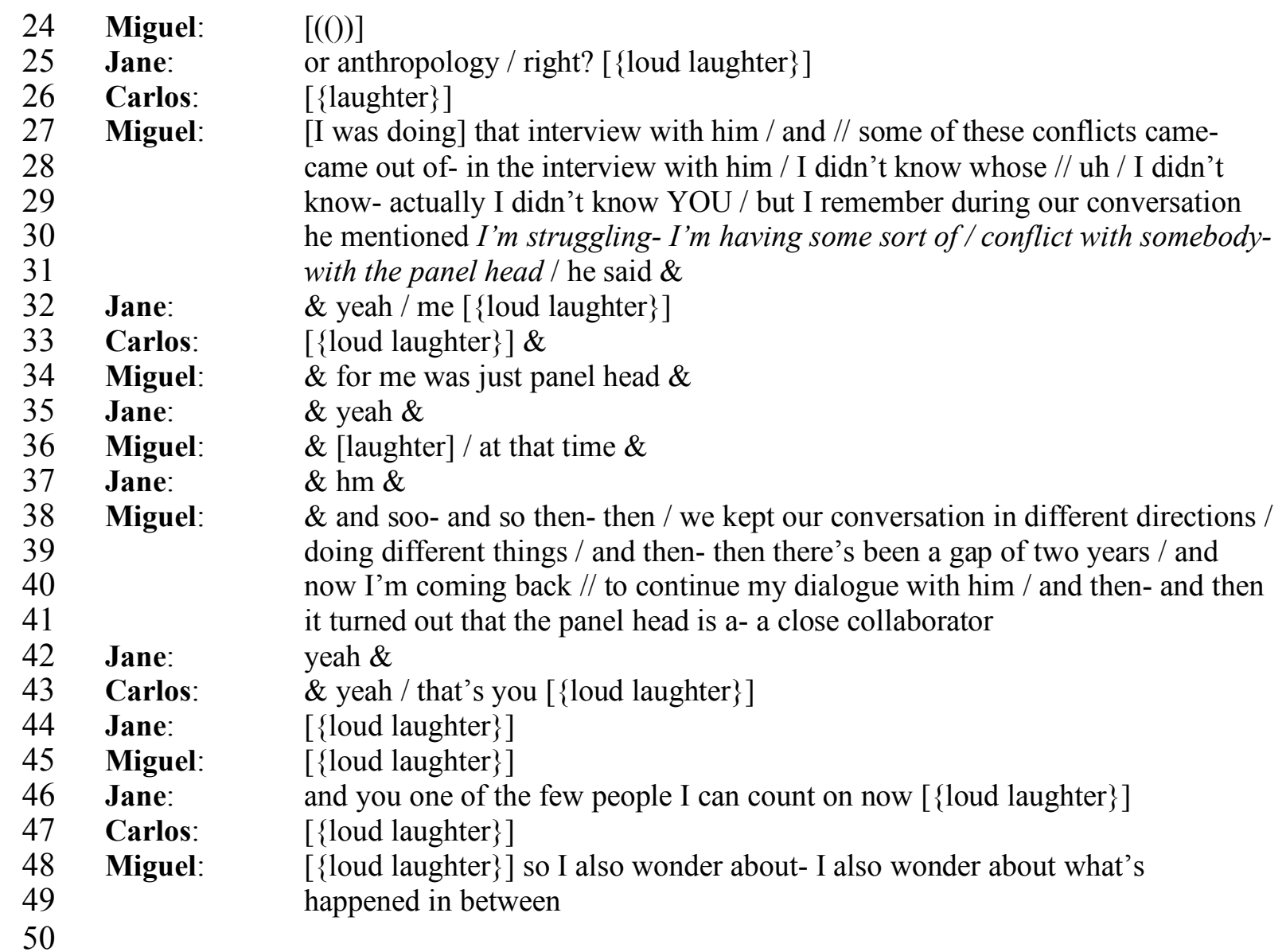

Carlos' request to go back three years prepares the terrain for the uncomfortable task of addressing his and Jane's past conflict (lines 1-5), this topicalization leading into a subsequent exchange sequence through which Jane and Carlos negotiate uneasiness via repetitive overlapped loud laughter (lines 6-49). These exchanges are also facilitated by Miguel's self-ascribed role as a 'cultural outsider' who needs an elaborated recount of the main shift in Carlos and Jane's relationship that turned their previous fights into mutual trust. But Miguel's role not only paved the way for Carlos and Jane to acknowledge their past conflicts; it also provided a platform for Jane to review the extenuating circumstances that rationalize the conflict's source, and thus to provide Carlos and Miguel with an opportunity to empathize with her past de-alignment with pedagogical progressivism's typifying features and the normative roles linked to it. 
In fact, the interview continues with Jane explaining her role in re-enforcing a pedagogical focus on grammar and vocabulary, which originated the conflict with Carlos, in relation to the Chinese majority's restricted access to English outside classrooms in the Hong Kong educational system. More specifically, a grammatical focus on English language teaching/learning is framed with reference to institutional 'spoon-feeding strategies' that help students to cope with educational system demands, even though they have very little English proficiency. Jane also justifies her initial stance on pedagogy by describing her 'overwhelming' and 'chaotic' (i.e. precarious and unpredictable) working conditions and teaching responsibilities during the first year at MAT.

Once this common ground is established, Jane and Carlos collaboratively detail Jane's teaching in the school's EMI section as an experience that triggered her shift in pedagogical stance, towards a greater concern over what is termed as 'literature-based curriculum approaches' in order to cater EM students' educational needs. Based on this collaboratively constructed alignment, Miguel follows by requesting to clarify Jane's teaching responsibilities at the time of the interview, which paves the road for Jane and Carlos to complete the action of repair and reconciliation through identification of wider structural inequalities in the education system and the dilemmas these generate at MAT:

\section{Extract 2. 'Now I'm actually caught in a dilemma'}

1 Miguel: but what's your- for example / what's your ((what grade are you teaching)) in

Jane: the international division?

Miguel: and you're still teaching four / the CMI students / or not?

Jane: one / 1.5 [\{laughter $\}$ a nightmare $]$

Miguel: [so you are still] ok / and who are you collaborating with in the / CMI division?

Jane: collaborating with? / I don't collaborate with anybody / I just work on my own/ 


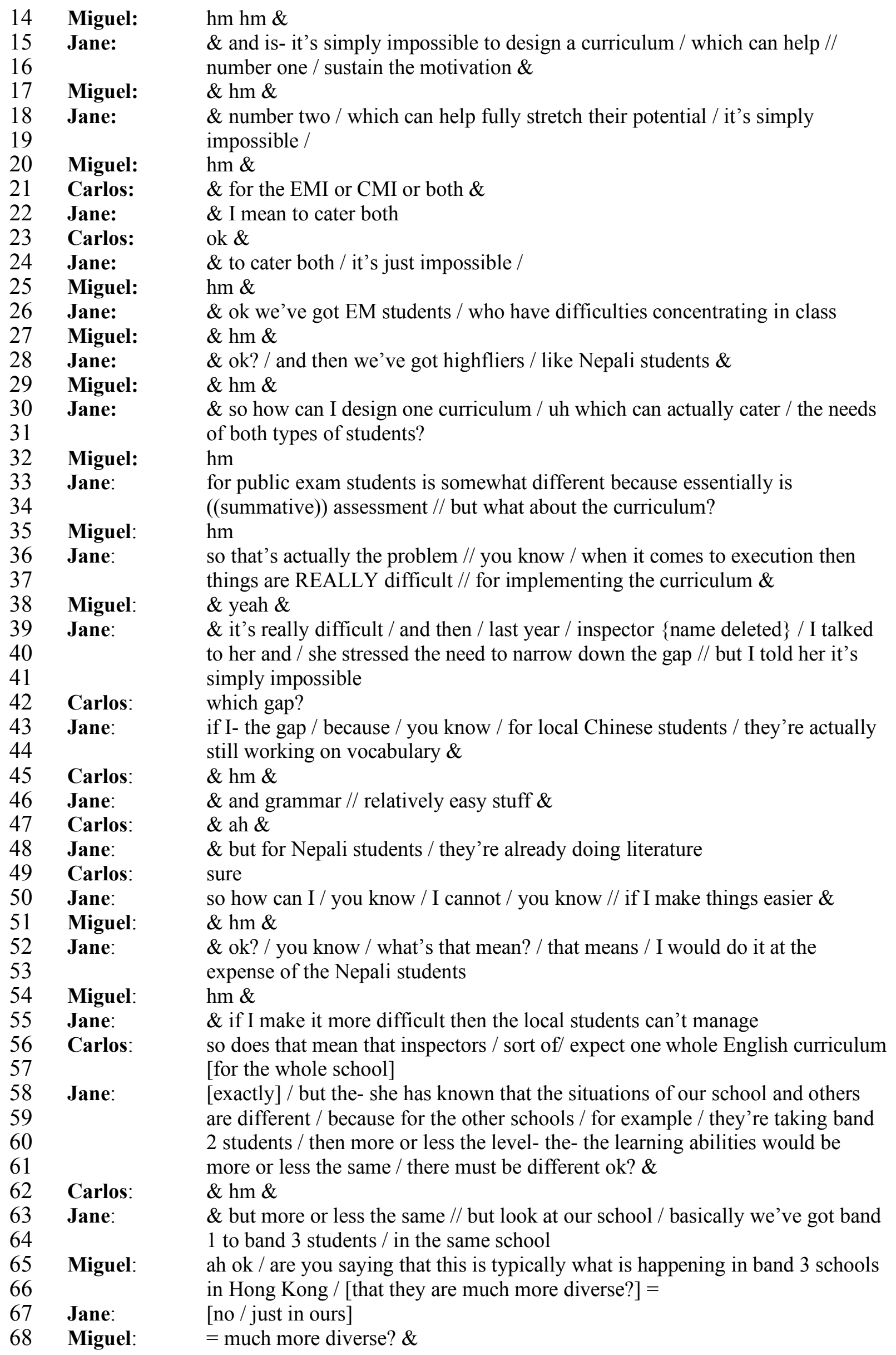


69 Jane: \& just in our school- just in our school- just in schools like ours / why / because

Carlos: we are going to (()) one of the few schools in [Hong Kong]

72 Jane: [the birthrate] is much greater yeah because we have to take any students / you know? / any human being

Miguel's attempts to understand the specific groups that Jane is teaching and the other school actors that she collaborates with lead the conversation towards a collaborative stance in which Carlos' guiding questions (lines 21, 42, 56), accompanied by Jane and Carlos' engagement in reciprocal positive evaluations (lines $23,49,58$ ) and intersubjective building on each other's contributions (lines 55-56-58, 69-71-72), foreground the dilemmas associated with the institutional standardization of English language education at MAT. Against a wider educational system that ranks schools and students according to their degree of alignment with the systemic institutional culture of spoon-feeding that established as a premise earlier in the course of the interview, increasing pressures for standardization are collaboratively placed by Jane and Carlos in the course of Extract 2 as further disadvantaging low prestige schools as these are more likely to serve a more diverse school population in terms of learning styles and background knowledge.

In MAT's case, this pressure is indexed through the existence of the EMI and CMI divisions whereby CMI students are presented as more aligned with the normative pedagogical focus on vocabulary and grammar while EMI students appear as more deviant, yet also more likely to be 'good' students in English compared to CMI students (lines 43-49). As a result, and in the context of this jointly-constructed alignment between Carlos and Jane, the latter presents herself as pedagogically paralysed in the daily curricular implementation since any action is likely to be seen as contributing to the exclusion of either CMI or EMI students (lines 1-55). At the same time, she sees the school as paralysed by lack of choice: both sets of students available to it are portrayed as lacking desirability within Hong Kong's education market (lines 56-72); as a 
commodity formulation, they are explicitly 'any human' with value attached only to their ability to fulfil a quota (line 71-72), implicitly denied the personae imagined in the discourse of pedagogical progressivism.

Following a change in the school's principal in May of 2014, Jane felt futile, and resigned. Lagan and Carlos remained, but after organising one last promotional event with students in July, and receiving new assurances of institutional support, were dismissed from their positions without notice in October 2014. Sixty parents and their children responded with a two-day school boycott, and many expressed anger with EM students' enrolment as a survival tactic. One parent, attempting to clarify that the boycott's aim was not to restore the dismissed teachers but to demand for quality education, expressed in a Facebook post: 'To all our community people, just wanna clear why and for what purpose we are fighting and stand for ? we parents and the students we are not fighting for the teacher who dismissed from the school, we just want our children good education and we are so disappointed that they are using our children just to survive the school...' The following year, several discontented senior secondary students, who upon recruitment had been promised opportunities for international qualification, enrolled in other schools, and another teacher previously recruited by Lagan was dismissed; by that time, pedagogical progressivism no longer played a role in the school's marketing efforts.

The implications of this abrupt ending are addressed below, in the last section of this article.

\section{Discussion: New structures for action and collusions of hope}

The dynamics we describe at MAT are not isolated, but part of a larger pattern in which institutions respond to pressures of deregulation, privatisation, and internationalisation by packaging educational features, (including pedagogy, curriculum, medium of instruction, 
and school organisation), alongside sets of values and social personae, into commodity formulations crafted with 'specific "peoples" and "communities" in mind' (Wilkins, 2012; p.166). This happens at schools lacking prestige and at schools discursively constructed as elite. Therefore, understanding how commodification processes shape inequality and affect the daily lives of social actors requires further inquiry situated in varying material conditions and discursive contexts.

At MAT, pedagogy was constructed as a discursive space in which social actors made sense of and responded to conflicts. These conflicts were related to changes in political economy attempting to reorient them and their rationalities towards market competition. While some discourses emphasised alarm with the possible loss of resources and school closure, others foregrounded concern over the life-chances of EM in a polarised social context and underscored that the crisis of enrolments could be solved by instituting and marketing pedagogical progressivism. The formulation of pedagogy in its commodity register was then not simply a local uptake of neoliberalism, but one through which discourses associated with neoliberalism at times were joined with existing discourses, and projects contradictory in character to neoliberalism. Indeed, as a discursive feature, pedagogy was not always or only a commodity; it took on commodity formulations at times when audiences became understood as 'consumers' and could orient themselves to such formulations, and lost those formulations when it became an emblem of ethnic empowerment.

Ultimately, the commodity register of pedagogy was dependent on the reflexive activities of actors at MAT, who took varying and flexible stances regarding the relevancy of its use values. The commodity formulation of pedagogy proposed to students, parents, and teachers claimed that it could be exchanged via enrolment or employment for new material conditions and subjectivities. Furthermore, it advocated transformation and 
empowerment of individuals and groups. Against this market, actors created new semiotic formulations in relation to conventional frameworks of economic exchange. In reflexively holding the school accountable for its promises of quality, critiquing the use of students for survival, and finding spaces for repairing relationships, various actors formed subjectivities and created meaning challenging the market metaphor. But to what extent did these local discourses maintain spaces in which neoliberalism asserted a hegemony that could be challenged and contested, but that ultimately remained a presence in social interactions? If we are committed to both critiques of neoliberal arrangements and providing alternatives, is there reason to believe that the stories set at MAT illustrate collusions as hope (McDermott \& Tylbor, 1986) in which actors could organise conditions for creative practice?

In answering these questions, we recognise that 'not all challenges to neoliberalism are liberatory ones,' (McElhinny, 2016, p. 190), and moreover, we prefer to refrain from presumptions that any particular institutional arrangement emerges as purely a reproduction of neoliberalism, or an alternative to it, and that political logics articulated and enacted as resistance to neoliberalism or its effects may not just reproduce existing inequalities and forms of marginalisation, but also generate new ones.

At MAT, a discursive space opened in which pedagogy became both a commodity formulation and a resource for discussing, theorising, and attempting to enact forms of participation beyond economic exchange. Rather than discourses of community, social justice, and solidarity being purely marginalised (Choi, 2005: p. 239), they circulated, mixed with, gave shape to, and were shaped by neoliberal logic of marketized education and competition. Teachers, students, and parents, in displays of reflexivity regarding the rationality of their own choices and institutional arrangements, challenged neoliberal expectations of self-reliant and self-actualised subjectivities. Moreover, they demanded 
some responsibility from the school and the educational system, even if in the end they found themselves without viable alternatives.

Teaching and learning spaces offering distinct institutional linguistic, social, and spatial/temporal arrangements became available to teachers and EM students in the IS, discursively promoted as ways of participating in local communities and in transnational knowledge economies. Yet these spaces were not available equally to all students in the IS, and mostly excluded students in the CMI section; neither publicizing pedagogy, as a commodity, to them in recruitment, nor effectively including them in conversations related to projects of empowerment.

Therefore, while the discursive project of pedagogical progressivism at MAT taken up by teachers, students, and parents ended with animosity, we must continue to look at the trajectories of individual and group actors. Attention should be paid to their continuing interactions with and reshaping of existing conventions, market opportunities, and institutional priorities to understand how both alignments with neoliberal formulations and alternate agendas of social change persist. For instance, in the two years following their respective departures from MAT, former IS teachers engaged with available market opportunities. Lagan took up work in the expanding online education market to bring international certification opportunities to former MAT IS students and students who had left other schools serving ethnic minorities. Jane became an international postgraduate student in the UK seeking critical perspectives to minority education, and Carlos, with the help of a MAT student, received a social entrepreneurship grant to prepare a group of his former MAT students for their public exams.

In other words, the practices of these actors continue to be shaped by neoliberalism, as their actions likewise continue to constitute it and challenge it. 


\section{Acknowledgements}

This work was supported by the University of Hong Kong's Seed Funding Programme for Basic Research.

APPENDIX: Symbols used in the transcripts

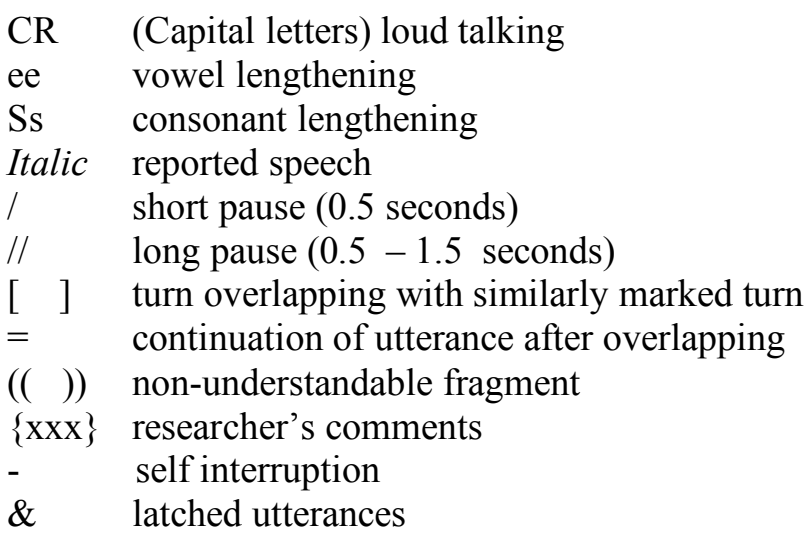

\section{References}

Agha, A. (2007). Language and social relations. Cambridge, UK: Cambridge University Press.

Agha, A. (2011). Commodity registers. Journal of Linguistic Anthropology, 21(1), 2253.

Allan, K., \& McElhinny, B. (2017). Neoliberalism, language and migration. In S. Canagarajah (Ed.), The Routledge Handbook on Language and Migration (pp. 99-121). New York: Routledge.

Apple, M. (1979). Ideology and Curriculum. Boston, MA: Routledge \& Kegan Paul.

Block, D. (forthcoming). What on earth is ‘language commodification’? In S. Breidbach, L.

Ku ster, \& B. Schmenk (Eds.), Sloganizations in language education discourse. Bristol: Multilingual Matters.

Blommaert, J. (2005). Discourse. A Critical introduction. Cambridge, UK: Cambridge University Press.

Chan, K. P. (2013, July). Ethnic minority-the savior of schools? Paper presented at the Education, Ethnicity, and Inequality Symposium: Issues and Insights, Hong Kong, S.A.R.

Cheong, C. Y. (2009). Hong Kong educational reforms in the last decade: reform syndrome and new developments. International Journal of Educational Management, 23, 65-86.

Choi, P.K. (2005). A critical evaluation of education reforms in Hong Kong: Counting our losses to economic globalisation. International Studies in Sociology of Education, $15(3), 237-256$. 
Codó, E, \& Patiño-Santos, A. (2017). CLIL, unequal working conditions and neoliberal subjectivities in a state secondary school. Language Policy. https://doi.org/10.1007/s10993-017-9451-5.

Del Percio, A. D. (2017). Engineering commodifiable workers: language, migration and the governmentality of the self. Language Policy. https://doi.org/10.1007/S10993-0179436-4

Dendrinos, B. (1992). The EFL textbook and ideology. Athens: Grivas Publications.

Duchêne, A., \& Heller, M. (Eds.). (2012). Language in late capitalism: Pride and profit. New York, NY: Routledge.

Education Commission. (2000). Learning for life, learning through life: Reform proposals for the education system in Hong Kong. Hong Kong: Government Printer.

Education Bureau. (2012). Study on the Provision of International School Places in Primary and Secondary Levels in Hong Kong. Hong Kong. Retrieved from http://www.edb.gov.hk/attachment/en/about-edb/publications-stat/research-reportabstracts/p1201e.pdf

Erni, J. N., \& Leung, L. Y. M. (2014). Understanding South Asian Minorities in Hong Kong. Hong Kong: Hong Kong University Press.

Flubacher, M-C., \& Del Percio, A. (Eds.) (2017). Language, Education and Neoliberalism: Critical Studies in Sociolingustics. Bristol: Multilingual Matters.

Foucault, M., Senellart, M., \& Collège de France. (2008). The birth of biopolitics : Lectures at the Collège de France, 1978-79. Basingstoke, UK; New York, NY: Palgrave Macmillan.

Giroux, H. (1988). Schooling and the Struggle for Public Life. Minneapolis, MN: University of Minnesota Press.

Goodwin, C., \& Duranti, A. (2000). Rethinking context: An introduction. In C. Goodwin, \& A. Duranti (Eds.), Rethinking context: Language as an interactive phenomenon (pp. 1-42). Cambridge, UK: Cambridge University Press.

Harris, K. (1979). Education and knowledge. London: Routledge \& Kegan Paul.

Harvey, D. (2005). A Brief History of Neoliberalism. Oxford: Oxford University Press.

Heller, M. (2007). Distributed knowledge, distributed power: A sociolinguistics of structuration. Text \& Talk 27(5-6), 633-653.

Heller, M. (2010). The commodification of language. Annual Review of Anthropology 39, 10114.

Heller, M., Pujolar, J., \& Duchêne, A. (2014). Linguistic commodification in tourism. Journal of Sociolinguistics 18(4), 539-566.

Jaspers, J. (2018). The transformative limits of translanguaging. Language \& Communication $58,1-10$. 
Jaworski, A. \& Thurlow, C. (2017). Mediatizing the 'super rich', normalizing privilege. Social Semiotics, 27(3), 276-287.

Lemke, (2001). 'The birth of bio-politics': Michel Foucault's lecture at the Collège de France on neo-liberal governmentality. Economy and Society 30(2), 190-207.

Leung, Y. Y. M. (2013). Education reform in Hong Kong: power-status, school strategy and social inequality (Doctoral dissertation). Retrieved from http://hdl.handle.net/1783.1/62278

Malinowski, B. (1923). The problem of meaning in primitive languages. In C. K. Ogden, \& I. A. Richards (Eds.), The meaning of meaning (pp. 296-336). New York, NY: Harcourt, Brace and World.

Martín-Rojo, L. (2018). Neoliberalism and linguistic governmentality. In J.W. Tollefson, \& M. Pérez-Milans (Eds.), The Oxford Handbook of Language Policy and Planning (pp. 544567). Oxford: Oxford University Press.

Marx, K. (1904 [1859]). A contribution to the critique of political economy. Chicago, IL: Charles H. Kerr.

McDermott, R., \& Tylbor, H. (1986). On the necessity of collusion in conversation. In: S. Fisher \& A. Dundas-Todd (Eds.), Discourse and Institutional Authority: Medicine, Education and Law (pp. 123-139). New York, NY: Ablex.

McElhninny, B. (2016). A Heartfelt Approach: On and Beyond Neoliberalism. Journal of the Society for Psychological Anthropology, 44(2), 186-191.

McGill, K. (2013). Political economy and language: A review of some recent literature. Journal of Linguistic Anthropology, 23(2), 196-213.

Neilson, D. (2015). Class, precarity, and anxiety under neoliberal global capitalism: From denial to resistance. Theory \& Psychology, 25(2), 184-201.

Pennycook, A. (1989). The Concept of Method, Interested Knowledge, and the Politics of Language Teaching. TESOL Quarterly, 23(4), 589-618.

Pérez-Milans, M. (2015). Mandarin Chinese in London education: Language Aspirations in a Working-Class Secondary School. Language Policy 14(2), 153-182.

Pérez-Milans, M., \& Soto, C. (2014). Everyday practices, everyday pedagogies: A dialogue on critical transformations in a multilingual Hong Kong school. In J. Byrd Clark, \& F. Dervin (Eds.), Reflexivity in language and intercultural education: Rethinking multilingualism and interculturality (pp. 213-233). New York, NY \& London: Routledge.

Pérez-Milans, M., Soto, C. (2016). Reflexive language and ethnic minority activism in Hong Kong: A trajectory-based analysis. AILA Review, 29(1), 48-82.

Popkewitz, T. (1984). Paradigm and Ideology in Educational Research: The Social Functions of the Intellectual. London: Falmar Press. 
Silverstein, M., \& Urban, G. (Eds.) (1996). Natural histories of discourse. Chicago, IL: University of Chicago Press.

Simon, R. I. (1987). Empowerment as a pedagogy of possibility. Language Arts, 64(4), 370382.

Simpson, W., \& O’Regan, J. P. (in press). Fetishism and the Language Commodity: A Materialist Critique. Language Sciences, 67(2).

Sunyol, A. (2017). Being Dealt a Bad Hand: Performing and enduring new student identities in the IB. Talk presented at the UCL IoE Applied Linguistics doctoral seminars, London.

Urciuoli, B. (2003). Excellence, leadership, skills, diversity: Marketing liberal arts education. Language \& Communication, 23(3-4): 385-408.

Urciuoli, B. (2008). Skills and selves in the new workplace. American Ethnologist, 35(2), 211 228.

Wilkins, A. (2012). Pedagogy of the consumer: The politics of neo-liberal welfare reform. Journal of Pedagogy/Pedagogický casopis, 3(2), 161-173.

Woo, D. (2014). Neoliberalism in Two Hong Kong School Categories. Current Issues in Comparative Education, 16(1), 37-48.

Zhou, Y., Cai, T., \& Wang, D. (2016). Social Segregation in Hong Kong's Schools: 2000-2012. Chinese Sociological Review, 48(3), 248-270. 